EPiC Series in Engineering
Volume 3, 2018, Pages 295-301
HIC 2018. 13th International
Conference on Hydroinformatics

\title{
Performance Analysis of the Water Distribution System of the City of Messina through Sustainability Indices
}

\author{
Iolanda Borzì ${ }^{1}$, Brunella Bonaccorso ${ }^{1}$ and Giuseppe Tito Aronica ${ }^{1}$ \\ ${ }^{1}$ Department of Engineering, University of Messina, Messina, Italy \\ iborzi@unime.it
}

\begin{abstract}
The main purpose of this study is to assess the performance of the water distribution system (WDS) of the city of Messina (Italy) under different management scenarios that can be operated by the local water utility, AMAM S.p.A. To this end, a methodology is here applied for determining sustainability indices for pressure in WDS. The sustainability indices are based upon performance criteria including reliability, resiliency and vulnerability. In particular, six different scenarios are analyzed and the results are compared in order to identify possible solutions to increase sustainability in WDS.
\end{abstract}

\section{Introduction}

In recent studies, water resources sustainability has been measured using reliability, resiliency, and vulnerability performance indicators. Numerous investigators have applied these performance indices differently in literature. For example, Li and Yang [1] defined sustainability in water use systems as equilibrium of network efficiency and resiliency. Piratla and Ariaratnam [2] modelled a sustainable WDS considering trade-offs between hydraulic reliability, life cycle cost and $\mathrm{CO} 2$ emissions. Tabesh and Saber [3] proposed a model using hydraulic (i.e. pressure index, pressure performance index, velocity performance index and reliability index), physical, and empirical indices for rehabilitation of water distribution network. Hamouda et al. [4] proposed an indicator-based methodology in order to evaluate vulnerability of water supply systems in the Eastern Nile Basin.

Loucks [5], in particular, introduced the Sustainability Index (SI) based on reliability, resiliency, and vulnerability. Aydin [6] had also aggregated the SI calculated for each node, into an overall SI for all the studied area divided into geographical zones and calculated SI for both pressure and water quality into a WDS.

In this study, the SI assessment is applied to the urban WDS of the city of Messina (Italy). Messina has a very complex WDS that has never been numerically modelled for simulating its hydraulical behavior. The purpose of this study is to develop a tool that can be used for elaborating and propose 
solutions to any critical issues. To do this, the water distribution system modelling is carried out by EPANET 2.0 [7], a widely used software developed by the "Water Supply and Water Resources Division" of the "U.S. Environmental Protection Agency's - National Risk Management Research Laboratory".

The values of node pressure are used to determine reliability, resiliency and vulnerability performance indices, which are then combined into a complete sustainability index (SI) for every node. All the metropolitan area is divided into zones, according to topography, and a combined SI calculation is performed to produce an overall sustainability score for every zone.

The proposed procedure is implemented by first considering two current scenarios of water distribution (intermittent water supply and continuous $24 \mathrm{~h}$ one). Then, two alternative solutions are analyzed for both the scenarios of intermittent water supply and continuous one. Totally six scenarios are here modelled and the SI is computed for every zone in each scenario.

\section{Material and Methods}

The EPANET software [7] is used for simulating the nodal pressures throughout the network over time using the extended period simulation (EPS), during 24 hours.

EPANET is a public domain, water distribution system modelling software package developed by the United States Environmental Protection Agency's (EPA), Water Supply and Water Resources Division. This software provides an integrated environment for editing network input data, running hydraulic and water quality simulations, and viewing the results in a variety of formats. EPANET provides also a fully equipped and extended period of hydraulic analysis that can handle systems of any size and supports the simulation of spatially and temporally varying water demand. The modelling provides information such as flows in pipes, pressures at junctions, propagation of a contaminant, chlorine concentration, water age, and even alternative scenario analysis.

\subsection{Sustainability Index Calculation}

Reliability, resiliency, and vulnerability performance indicators are calculated for each node and then aggregated into the SI.

A sustainability index (SI) is a term that indicates the performance of a water system with respect to predetermined thresholds of a satisfactory state $[3,5]$. In order to calculate the performance of the system, the satisfactory state and unsatisfactory state should be distinguished in mathematical terms.

The SI in terms of pressure for each zone is calculated by aggregating the entire SI of the corresponding nodes.

\subsubsection{Sustainability Index Calculation for each Node}

The SI is a weighted combination of reliability, resiliency, and vulnerability which may change over time and space [3,5]. The following definitions of reliability, resiliency, and vulnerability follow the work of Hashimoto et al.[8]. Reliability $(\boldsymbol{R E} \boldsymbol{L})$ is the probability that the WDS is in a satisfactory state defined as:

$$
R E L_{k, i, j}=\frac{\# \text { of times satisfactory occurs }}{\text { total \# of time steps }}
$$


where $\boldsymbol{k}$ refers to nodal pressure or water age at node $\boldsymbol{j}$ in zone $\boldsymbol{i}$. Resiliency $(\boldsymbol{R E S})$ represents how fast the system recovers from a failure defined as:

$$
R E S_{k, i, j}=\frac{\# \text { of times satisfactory follows unsatisfactory }}{\text { total \# of time unsatisfactory occurs }}
$$

Vulnerability ( $\boldsymbol{V} \boldsymbol{U} \boldsymbol{L})$ is the magnitude or duration of an unacceptable state of WDS in a certain time scale. In this study, vulnerability is defined as:

$$
V U L_{\mathrm{k}, \mathrm{i}, \mathrm{j}}=\frac{\sum \text { unsatisfactory values }}{\sum \text { all values }}
$$

Upper and lower limits of nodal pressure, which represents the sustainable range, are identified. In particular in this study, following the national regulations (Decree of the Prime Minister on March 4 1996) the satisfactory state for nodal pressure $\boldsymbol{P}_{\boldsymbol{i}, j, t}$ (pressure at node $\boldsymbol{j}$ in zone $\boldsymbol{i}$ at time $\boldsymbol{t}$ ) is assumed to be from $30 \mathrm{~m} \mathrm{H}_{2} \mathrm{O}$ to $70 \mathrm{~m} \mathrm{H}_{2} \mathrm{O}$ at the final delivery points.

The following SI definition proposed by Sandoval-Solis et al. [9], is used to calculate the SI for water distribution systems.

$$
S I_{k, i, j}=\left[R E L_{k, i, j} * R E S_{k, i, j} *\left(1-V U L_{k, i, j}\right)\right]^{1 / 3}
$$

The main feature of the SI is that it ranges from 0 (i.e. the lowest degree of sustainability) to 1 (highest degree of sustainability). Another property is that if any one of the performance criteria is zero then the overall SI will be zero. In this study, values of SI will be considered as reported in Table 1.

\begin{tabular}{lll}
\hline SI Range & State \\
\hline $0-0.25$ & Unacceptable \\
& $0.25-0.5$ & Moderate \\
\cline { 1 - 1 } $0.5-0.75$ & Acceptable \\
\cline { 1 - 1 } $0.75-1$ & Ideal \\
\hline
\end{tabular}

Table 1 - Sustainability Index Ranges

\subsubsection{Sustainability Index Calculation for each Zone}

The next step is to generalize the node performances to the corresponding zones in the network. For this purpose, the methodology proposed by Aydin et al. [6] is here applied: each node is weighted by the corresponding water demand, which indicates the population affected by poor performance of WDS. The following function is used to calculate the SI of each zone:

$$
S I_{k, i}=\frac{\sum_{j=1}^{N J_{i}} D_{i, j, \text { daily }} S I_{k, i, j}}{\sum_{j=1}^{N J_{i}} D_{i, j}}
$$

where $\boldsymbol{S} \boldsymbol{I}_{k, i}$ is the SI in terms of pressure $(k=P)$ in zone $\boldsymbol{i}, \boldsymbol{N} \boldsymbol{J}_{\boldsymbol{i}}$ is the total number of nodes in zone $\boldsymbol{i}$, $\boldsymbol{S} \boldsymbol{I}_{k, i, j}$ is the SI in terms of pressure at node $\boldsymbol{j}$ in zone $\boldsymbol{i}$, and $\boldsymbol{D}_{i, j}$, daily is the daily demand of node $\boldsymbol{j}$ in zone $i$. 


\subsection{Case Study}

The configuration of the water distribution network of Messina implemented in EPANET consists of 4000 nodes and more than 4400 pipes (Figure 1). The system is supplied by 2 different aqueducts and more than 25 different tanks, connected to each other with pumping connections or gravity ones (Figure 2). It is worth pointing out that the WDS here analysed was built before 1996 and that almost all buildings are equipped with domestic water pressure tanks that disconnect from the network, so that possible overpressures ( $>70 \mathrm{~m} \mathrm{H}_{2} \mathrm{O}$ ) are not perceived by users.

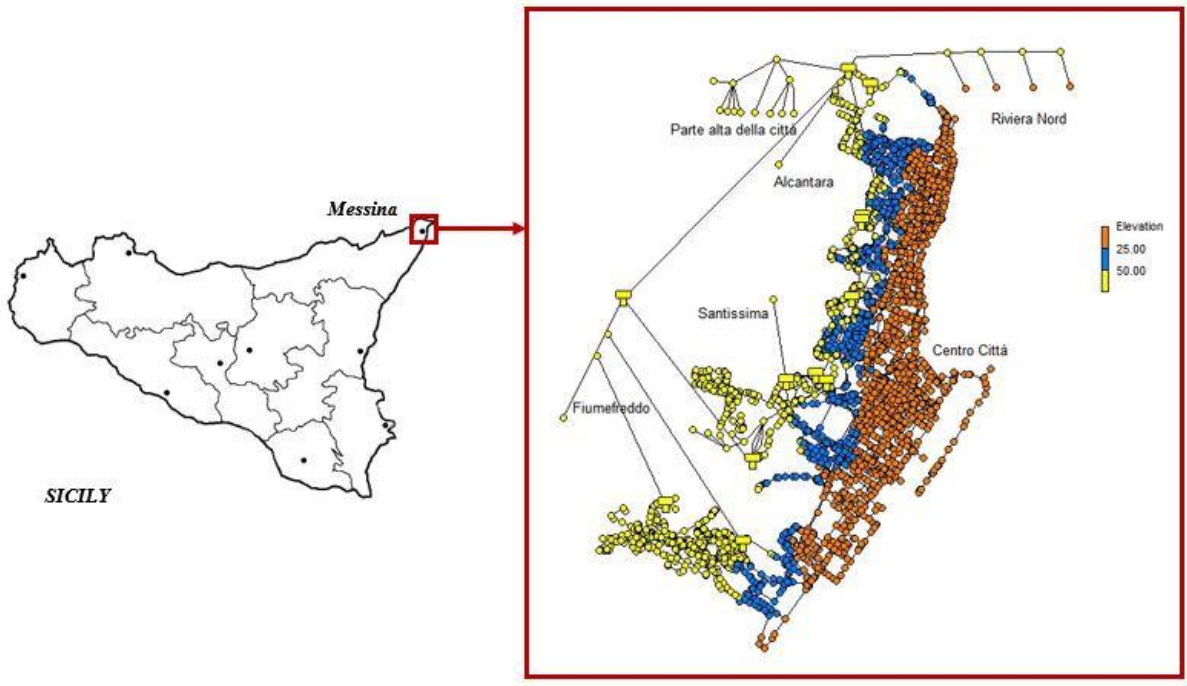

Figure 1 - Zones of Messina Water Distribution System

The water distribution network is divided into three different zones based on their altitude, in particular: the first zone identifies all the nodes below $25 \mathrm{~m}$ above sea level, the second zone identifies the nodes between 25 and $50 \mathrm{~m}$ and the third zone the nodes above $50 \mathrm{~m}$ (Figure 1).

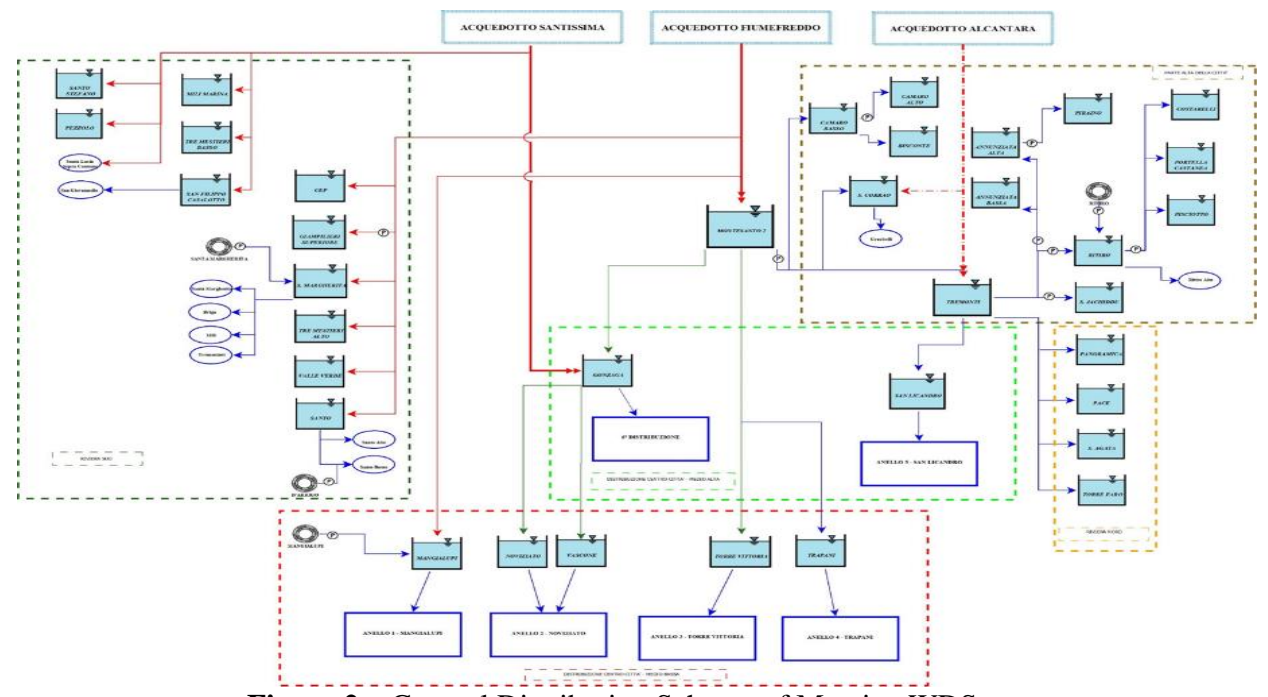

Figure 2 - General Distribution Scheme of Messina WDS 


\subsubsection{Water Distribution Patterns}

The procedure is carried out by considering two different scenarios of water distribution, namely: an intermittent water supply, with a distribution pattern of 19 hours (Figure 3) that is the current scenario and a continuous water supply, whose pattern is shown in Figure 5, that in spite of being a better option for users, it is not applied by AMAM in order to reduce energy costs from pumping water h24.

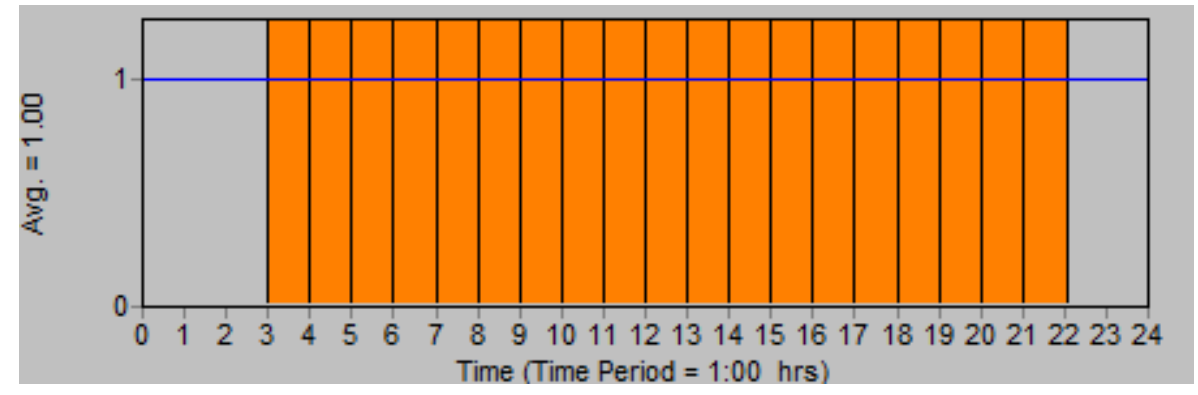

Figure 3 - Distribution Pattern of 19 hours for Messina WDS

In the 18 hours distribution pattern (Figure 3), differently from the h24 one, the water distribution appears to be constant in the 19 hours of distribution (from 3:00 to 22:00). The necessity of this kind of modelling is explained by the fact that almost every single user, in order to compensate the water absence during the night, is furnished by private tanks connected to WDS. In fact, private tanks work like private compensation tanks, that accumulate water resource constantly during the day and release that whenever it occurs. This mechanism turns into a constant request of water from the WDS, therefore a constant distribution pattern is considered into the EPANET mathematical model, given the inherent limitation of EPANET to simulate private tanks. In confirmation of that, output flow trends have been analyzed for every single tank of the WDS, by means of the observed records by telemetry stations. In Figure 4, an example of output flow trend from a tank of Messina WDS is reported.

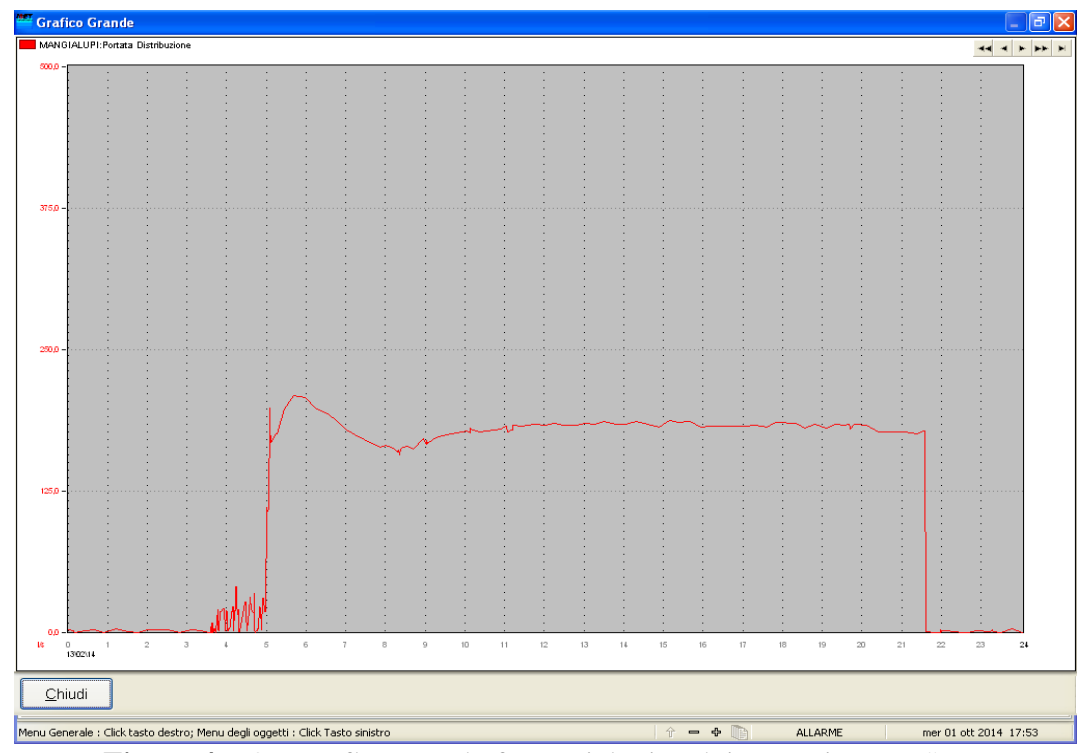

Figure 4 - Output flow trend of Mangialupi tank in Messina WDS 
The continuous distribution pattern (Figure 5), instead, is not constant during the day but follows a distribution trend that has been experimentally determined by records of water demand level observed into an experimental site in the city center of Messina.

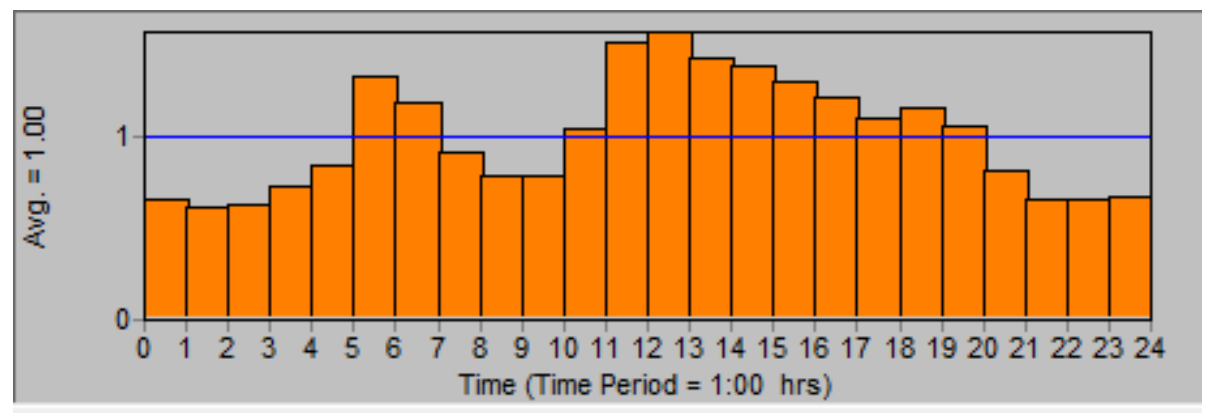

Figure 5- Distribution Pattern of 24 hours for Messina WDS

\subsection{Proposed Operating Scenarios}

When the established range of pressures is not respected, two different solutions are proposed. The first option would be the introduction of a new municipal water tank called "Montesanto1", located at high altitude (159 meters on sea level), in order to reduce pumping connection for some part of the system and improve pressure levels. The second option would be the reduction of water losses in all the WDS, by extraordinary maintenance works. In this case, considering the limitation of EPANET in dealing with pressure-deficient conditions, the reduction of water losses in the WDS is modelled as a uniform distributed reduction of water losses, that in term of EPANET model turns into a proportional reduction of nodes output flow. For both proposed solutions, the above-mentioned procedure for calculating SI indices is repeated, in both intermittent and continuous water supply conditions, to identify SI for every zone in each scenario.

\section{Results and Discussion}

As it is shown in Table 2, the proposed solutions slightly improve the sustainability index values for each scenario. From the analyses it can be observed that the most critical zone in each scenario is the third one (altitude > 50m), mainly in the intermittent water supply condition. Since the third zone is the one more affected by low pressures, it is the one that best benefits from the reducing losses solution, which cause higher pressure values all over the network. Instead, in the scenario with Montesanto 1 tank, overpressures of zones 1 and 2 decrease, so that SI increases. As expected, in all the zones and for all the analyzed scenarios, SI values are higher in the condition of continuous water supply than in the intermittent water supply configuration. Thus, a continuous distribution is recommended for improving performance of the WDS. 


\begin{tabular}{cccccccccc}
\hline & \multicolumn{3}{c}{ Current Scenario } & \multicolumn{3}{c}{ With Montesanto1 Tank } & \multicolumn{3}{c}{ Reduction Losses } \\
\hline Zones & $<25$ & $25-50$ & $>50$ & $<25$ & $25-50$ & $>50$ & $<25$ & $25-50$ & $>50$ \\
\hline $\begin{array}{c}24 \mathrm{~h} \\
\text { distrib. }\end{array}$ & 0.764 & 0.687 & 0.387 & 0.773 & 0.692 & 0.401 & 0.707 & 0.667 & 0.494 \\
$\begin{array}{c}19 \mathrm{~h} \\
\text { distrib. }\end{array}$ & 0.495 & 0.520 & 0.240 & 0.500 & 0.526 & 0.238 & 0.475 & 0.506 & 0.284 \\
\hline
\end{tabular}

Table 2 - Sustainability Index Values

\section{Conclusion}

The implementation of SI as performance indicator of water distribution systems could be a valid method for detecting critical zones, thus helping decision makers to improve water supply service. In fact, the index enables to assess easily advantages and disadvantages of each scenario in terms of reliability, resilience and vulnerability. In conclusion, the original and innovative aspects of this work with respect of the state of art is that this methodology can be a useful tool for water managers to evaluate the improvements in performances of water distribution systems, also when numerous scenarios are analyzed and compared each other, so it can be used as simple and immediate criteria to establish a primary list of priority in choosing the right and immediate way to improve water supply service and to fix possible failings. Future applications of SI would be oriented to include economic considerations in performance analysis of WDS.

\section{References}

[1] Li Y, Yang ZF. Quantifying the sustainability of water use systems: calculating the balance between network efficiency and resilience. (2011) Ecol Model 222:1771-1780

[2] Piratla KR, Ariaratnam ST. Reliability based optimal design of water distribution networks considering life cycle components. (2012) Urban Water J 9(5):305-316

[3] Tabesh M, Saber H. A prioritization model for rehabilitation of water distribution networks using GIS. (2012) Water Resour Manag 26:225-241

[4] Hamouda MA, El-Din MMN, Moursy FI. Vulnerability assessment of water resources systems in the Eastern Nile Basin. (2009) J Water Resour Manag 23:2697-2725.

[5] Loucks DP. Quantifying trends in system sustainability. (1997) Hydrol Sci J 42(4):513-530

[6] Aydin N, Mays L, Schmitt T. Sustainability assessment of Urban Water Distribution System. Water Resour Manage (2014) 28:4373-4384

[7] Rossman L.A. EPANET 2 users manual. (2000) U.S. Environmental Protection Agency, Cincinnati

[8] Hashimoto T, Stedinger JR, Loucks DP. Reliability, resiliency and vulnerability criteria for water resource system performance evaluation. (1982)Water Resour Res 18(1):14-20

[9] Sandoval-Solis S, McKinney DC, Loucks DP. Sustainability index for water resources planning and management. (2011) J Water Resour Plan Manag 137(5):381-390 